\title{
ESPAÇO E SUBJETIVIDADE NA GEOGRAFIA DE DONA BENTA (1935), DE MONTEIRO LOBATO: APORTES GEOGRÁFICOS E LITERÁRIOS
}

\author{
Filipe Rafael Gracioli ${ }^{1}$ \\ João Pedro Pezzato²
}

\begin{abstract}
RESUMO: Apresentamos em nossa escrita uma relação entre a Geografia de Dona Benta (1935) de Monteiro Lobato, ambos texto e autor posicionados como pináculos entre as narrativas dirigidas à infância leitora no Brasil e na América Latina e o movimento de seu empréstimo como livro escolar na escola pública brasileira à época de sua publicação. Por resgatar uma experiência de leitura apoiada na subjetividade do leitor, a narrativa subverte os cânones literários, o fazer geográfico de seu tempo e o entendimento sobre o ser criança, e inaugura junto à Literatura e à Geografia um olhar espacial pautado na imaginação criativa e na geograficidade, sem deixar de lado o tom de crítica necessário ao momento histórico de sua produção. De importância singular, a narrativa posiciona-se ainda hoje entre a juventude leitora brasileira como literatura de referência para a cultura infanto-juvenil.
\end{abstract}

Palavras-chave: geografia, literatura infantil, geografia escolar, livro didático, subjetividade.

\section{ESPACE ET SUBJECTIVITÉ DANS LA GÉOGRAPHIE DE DONA BENTA (1935), PAR MONTEIRO LOBATO: CONTRIBUTIONS GÉOGRAPHIQUES ET LITTÉRAIRES}

RÉSUMÉ: On présente dans notre écriture une relation entre la Géographie de Dona Benta (1935), par Monteiro Lobato, tous les deux, récit et auteur, positionnés comme des pinnacles au milieu des récits orientés à l'infance lecteure au Brésil et en Amérique Latine et le mouvement de son prête comme livre scolaire pour l'école publique brésilienne à l'époque de sa publication. De façon à récupérer une expérience appuyée dans la subjectivité du lecteur, le récit subvertit les canons littéraires, le savoir-faire géographique à son temps et la compréhension sur l'être enfant et, aussi, fait débuter ensemble à la Littérature, bien comme à la Géographie une perspective spatiale fondée sur l'imagination créative et dans la géographicité, sans mettre à côté le ton de critique nécessaire au moment historique de sa production. Singulier, le recit se positionne même aujourd'hui au milieu de la jeunesse brésilienne comme lecture de référence pour la culture infanto-juvénile.

Mots clés: géographie, littérature infantile, géographie scolaire, livre didactique, subjectivité.

\footnotetext{
${ }^{1}$ Professor Doutor lotado no Instituto do Patrimônio Histórico e Artístico Nacional - IPHAN/CLC Rio de Janeiro-RJ. E-mail: filipe-rg@hotmail.com/filipe.gracioli@iphan.gov.br

${ }^{2}$ Professor Doutor lotado no Depto. de Educação da Universidade Estadual Paulista "Júlio de Mesquita Filho" - UNESP Campus Rio Claro. E-mail: jpezzato@ rc.unesp.br
} 


\section{INTRODUÇÃO}

O texto que apresentamos é parte da pesquisa de doutoramento intitulada Língua, literatura e geografia. Uma experiência de leitura da Geografia de Dona Benta, de Monteiro Lobato e do Le tour de la France par deux enfants, de G. Bruno, publicada em 2018. Aqui, nosso propósito será o de apresentar ao leitor a relação entre um livro de lazer dirigido à infância leitora do início do século XX, a Geografia de Dona Benta (1935), de autoria de Monteiro Lobato e o seu empréstimo como livro escolar à época de sua publicação, situando-se como fonte para a história e a historiografia da geografia escolar como um campo de saber afeto à escola e à ciência geográfica de referência.

Nossa hipótese investigativa caminha no sentido de que Monteiro Lobato funda, para o campo da literatura infantil no Brasil e na América Latina, com a sua narrativa literária de teor geográfico, uma maneira inovadora de situar a criança em sua experiência como leitora do espaço geográfico, trazendo-a para o centro desta tarefa e posicionando-a como criadora de sua própria experiência espacial, a partir de suas visões de mundo, sentidos, desejos e subjetividades. Frente a este paradigma inovador de se pensar e de se conceber a criança leitora e sua experiência espacial, sua narrativa será tomada de empréstimo pela política educacional escolar pública vigente à época de sua produção, conferindo-Ihe caráter de livro escolar, algo também bastante inovador para o seu momento histórico.

Justificamos nosso estudo com o entendimento de que uma investigação com este teor aproximativo entre distintos campos de conhecimento seja necessário para trazer à luz algo jamais visto tanto para a literatura infantil, ao valer-se de elementos da imaginação, da ficção e da subjetividade para se pensar conceitos até então científicos e de base lógico-positivista, rompendo com os cânones do fazer literário no país e no mundo, quanto para a geografia escolar, ao instaurar um entendimento de espaço a partir de conceitos extra científicos, tangentes à subjetividade em sua constituição.

Objetivamente, nossa escrita caminha no sentido de que a geografia escolar no Brasil buscou para a composição de seu escopo conceitual não somente o conhecimento geográfico da ciência de referência, mas também, lançou mão de constituir-se por outras fontes, iniciando-se, conforme indica e como verificaremos em Monteiro, antes mesmo no seio das narrativas que tinham o espaço geográfico não apenas como pano de fundo, mas também como palco para o desenvolvimento das ações a se desempenharem nas suas tramas.

\section{OS CAMINHOS DA INVESTIGAÇÃO: CONCEITOS, MÉTODOS E METODOLOGIAS}

Podemos considerar que, se desde os primórdios da escrita formal a representação do espaço era tomada apenas como suporte para o desenvolvimento da ação do cotidiano, como nos revelam as pinturas rupestres e os primeiros sistemas linguísticos, será com o desenvolvimento da linguagem como possibilidade de atribuição de significados aos signos do real e com a instituição da literatura como expressão de uma sistema representativo de uma cultura com base no registro das oralidades por meio da escrita de narrativas (e, por extensão, das experiências de seus contadores) que a perspectiva de espaço começará a se redimensionar. Porém, agora não mais somente sendo tomado como materialidade pura ao acontecimento da vida - o que podemos denominar de suporte para o desenvolvimento das ações - 
mas, principalmente, encarado como integrado ao desenvolvimento da ação cotidiana, ao acontecimento da vida, especialmente compreendido como expressão de subjetividades.

Adjetivado como geográfico, o espaço passa então a ser não apenas receptáculo, mas protagonista da trama apresentada pelas narrativas, funcionando como agente mobilizador e atribuidor de poderes às ações no encaminhamento dos fatos. Monteiro considera que a literatura em diálogo com a Geografia vem para significar uma saída que leva à criação de geograficidades - a partir das subjetividades de seus leitores, de suas fantasias e visões de mundo - aos lugares do fazer e da técnica, conferindo ao espaço, mas, sobretudo, ao homem, uma possibilidade de identificação e autorreconhecimento, a partir da dimensão espacial geográfica. Segundo o autor:

[...] excetuadas a ficção científica, a fantasia e a alegoria - a noção de "lugar", embora sendo obra de imaginação e de criação literária, contém uma verdade que pode estar "além" daquela advinda da observação acurada, do registro sistemático dos fatos. Esta capacidade paradoxal encontrável na Literatura, ou a ela conferida pelo geógrafo, brota de um reconhecimento de que a essência ou a verdade do mundo transcende à interpretação de dados coligidos por geógrafos, historiadores e sociólogos. Não se trataria, de nenhum modo, de substituir a análise científica pela criação artística, mas apenas retirar desta (Literatura) novos aspectos de "interpretação", reconhecê-la como um meio de enriquecimento. (MONTEIRO, 2002, p. 14-15 - grifo nosso).

Por entendermos que a narrativa de Monteiro Lobato se situa no campo da literatura infantil, oferecendo ao leitor de sua época uma possibilidade de reinvenção do ler e do fazer uma escrita e uma leitura para crianças em alfabetização, principalmente, esta narrativa aponta para uma escrita inovadora e sem referências pregressas, o que a torna um verdadeiro pináculo literário.

Além da possibilidade de leitura voltada ao lazer e ao letramento, os bastidores de suas linhas nos instigam à indagação pela visão de mundo de seu autor; apesar do tom de manifestação pessoal, como de encantamento ou mesmo desencantamento com o real, a Geografia de Dona Benta se posiciona no momento de sua produção como objeto cultural, parafraseando Cevasco (2003) ao apontar que o livro insere-se na história como patrimônio cultural e pode ser tomado como objeto portador de ideologia, cultura e valor, dado que as "formas de vida de uma sociedade moldam seus produtos e obras." (CEVASCO, 2003, p. 65).

Nesta mesma lógica, a narrativa em foco apresenta-se também como objeto cultural escolar, tendo sua aplicação ora estimulada, ora desencorajada pelo pensamento político vigente às políticas educacionais de sua época, inicialmente de caráter moralista e, posteriormente, admitindo uma feição atrelada ao paradigma construtivista, o qual pode ser compreendido como uma tentativa de entender 0 fenômeno do ensino como busca de compreender a educação em sua dimensão psicológica, que busca orientar as práticas escolares para o desenvolvimento pleno das capacidades psicológicas das crianças e dos adolescentes sem omitir demais dimensões da cultura escolar. 


\section{BUSCAR OS SINAIS: O PARADIGMA INDICIÁRIO COMO REFERENCIAL METODOLÓGICO}

Carlo Ginzburg, com o seu paradigma indiciário, oferta-nos uma possibilidade de olhar para o espaço geográfico sublinhado na narrativa da Geografia a partir de uma interpretação ampla, a qual nos oferece a possibilidade de compreender o espaço narrado a partir do ser-no-mundo, ou seja, a partir de nossa visão de mundo, extrapolar os limites canônicos da ciência e vagar pela dimensão mais aproximada possível do real: a do eu e de suas possibilidades de versões sobre o espaço.

Conforme sua proposta, uma leitura atenta aos sinais, aos indícios de uma narrativa levam-nos ao entendimento de uma possibilidade de leitura do texto que tende para a expressão de sua veracidade. Segundo o autor, o paradigma indiciário assemelha-se à investigação atenta de obras de arte, onde o pouco convencional torna-se relevante; à semelhança de uma investigação criminal, na qual as pistas e os sinais que revelam indícios de uma cena indicam o caminho até o criminoso, assim também os sinais que a narrativa vai significando, à medida da subjetividade do leitor, aproximam-lhe de uma interpretação possível para o espaço geográfico e seus desdobramentos na trama.

O paradigma indiciário justifica-se pela noção de que os sinais nos permitem compreender os pontos pouco luminosos da realidade, competindo à intuição, permitida pelos sentidos humanos, captar tais indícios. Conforme o autor: "Se a realidade é opaca, existem zonas privilegiadas - sinais, indícios - que permitem decifrá-la. Essa idéia, que constitui o ponto essencial do paradigma indiciário ou semiótico, penetrou nos mais variados âmbitos cognoscitivos, modelando profundamente as ciências humanas." (GINZBURG, 1999, p. 177).

Assim, "faro, golpe de vista, intuição" (GINZBURG, 1999, p. 179) compõem os procedimentos para se analisar uma cena ou, em nosso caso, um texto narrativo, com a defesa de que o rigor do método se garante não pela sua referência a um modelo estabelecido a priori, e que este rigor é não só inatingível, mas também, indesejável, já que "as formas de saber mais ligadas à experiência cotidiana [...] são, aos olhos das pessoas envolvidas, decisivas." (GINZBURG, 1999, p. 178-179).

Buscar pelos indícios, pelos sinais que acusam a subjetividade do leitor dentre as linhas escritas e dentro dos possíveis contextos interpretativos, será nosso propósito metodológico, admitindo que nosso olhar de leitores concebe a narrativa como o contar da própria experiência, à diferença do romance, que conta a partir da experiência de outrem.

\section{A GEOGRAFIA DE DONA BENTA, DE MONTEIRO LOBATO}

Publicada em 1935, a Geografia de Dona Benta é um livro de Monteiro Lobato que narra a viagem imaginária das personagens da obra Sítio do Pica-pau Amarelo pelos continentes do planeta Terra a bordo de um navio também imaginário, o Terror dos Mares. Nesta viagem, feita à base de muita conversa, portanto, em resgate a um elemento já bastante descontinuado à época de Lobato, a oralidade, o modo de Lobato fazer Geografia destoa da tradição enciclopedista e decorativa atribuída ao conhecimento geográfico de seu tempo.

$\mathrm{Na}$ trama desenvolvida, as personagens do Sítio do Pica-pau Amarelo, Dona Benta, a avó-mulher-líder, Tia Nastácia, a mulher, negra, ex-escravizada-braço direito de Dona Benta, Pedrinho, o garoto fantasioso-corajoso e Narizinho, a garota sonhadora-independente, junto a seus companheiros inventados, a boneca Emília e 
o sabugo de milho Visconde de Sabugosa, viajam pelo mundo a partir do quintal do sítio de Dona Benta, em meio a prosas e viagens fantásticas, percorrendo itinerários imaginários por todos os continentes do mundo (exceto a África), conhecendo culturas e modos de viver, de ser e de estar no espaço. Não há limites de tempo nem mesmo de espaço; há apenas a imaginação, que conduz a todos por lugares e territórios onde a tônica se faz pelo pensamento de criatividade para contornar os desafios que se vão apresentando pelas tramas.

De uma construção dialógica, o texto de Lobato vai se pontuando pela inserção do leitor como participante da trama, convidando-o a viajar junto das personagens. Organizados a partir de descrições topográficas introdutoras, porém breves, tais diálogos situam e ao mesmo tempo inserem o jovem leitor na cena contada, representado pelas personagens que questionam, recortam, reinventam os olhares para os espaços por elas visitados. Também, críticas contundentes ao modo de produção do espaço e da vida da época são abundantes na trama, em que a boneca de pano Emília, "remendada, propositalmente sem alma e sem coração" - e brilhantemente costurada por Monteiro Lobato para servir-lhe de porta-voz - encontra uma maneira de se colocar nas cenas, territórios e lugares visitados, com a intenção de subverter o fazer geográfico de então. O diálogo entre a boneca, Dona Benta e Narizinho, transcrito na sequência, é amostra do apontado:

- Por que se chama Rio de Janeiro essa cidade?

- Por que os portugueses, quando descobriram a baía acharam-na com jeito de Estuario dum rio...

- Estuario? Que é isso?...

- Estuario quer dizer Foz de rio, isto é, o ponto onde um rio despeja no mar, mas uma foz que se alargou mais que o comum, formando uma espécie de baía. O Rio da Prata, por exemplo, é o estuario do Rio Paraná. Esses antigos portugueses, porém, se enganaram, visto que a Guanabara é baía e não estuario de rio nenhum. E como houvessem descoberto o falso estuario num dia do mês de janeiro, deram-lhe o nome de Rio de Janeiro, como quem diz "o rio descoberto em janeiro". Ali desembarcaram e ali começaram a conquistar a cidade que é hoje a capital do Brasil, com quasi dois milhões de habitantes.

Narizinho apontou a luneta para a capital brasileira afim de ver as mil coisas lindas que ela apresenta.

- Ha uma avenida que vai de mar a mar...

- Avenida Rio Branco, explicou dona Benta.

- Ha outra cidade menor do outro lado da baía... [sic.] (LOBATO, 1935, p. 61).

Monteiro Lobato se posiciona no meio intelectual de sua época com textos revolucionários do ponto de vista do protagonismo das personagens na literatura infantil brasileira, entre os quais se insere a Geografia de Dona Benta, ao introduzir o conceito de desliteraturização, a maneira por ele encontrada para contornar a obrigação do contar imposta pela língua, bem como de inserir a experiência de leitura na própria leitura, o fazer o leitor sentir-se identificado com o texto, a partir de uma linguagem que se abre para a possibilidade da subjetividade da leitura e da interpretação pelo fantástico e pela imaginação.

$\mathrm{Na}$ sua escrita, as crianças, por meio de sua experiência leitora, protagonizam as tramas, inventam, criam, reconstroem o fazer literário e rompem com os cânones da literatura dirigida à infância de seu tempo, ao inaugurarem algo impensável até 
então: posicionar a criança no centro de sua experiência leitora. Não por acaso, o emprego do sinal ortográfico das reticências é abundante nos diálogos tecidos pelas personagens, como possibilidade de reflexão, do ouvir e do falar, do dar o tempo e o espaço para a inclusão das vezes e das vozes:

Dona Benta continuou:

- Foi ali o ninho da humanidade. Ali se chocaram os ovos das grandes raças e ali se chocou a Lingua...

- Como? Que lingua?

- Uma lingua geral, uma lingua basica de que todas as grandes linguas modernas mostram vestigios. E' ali a verdadeira divisão da Europa e da Asia. [...] Reparem que nesse centro da Asia existe um lago imenso...

- Estou vendo! Estou vendo até dois, um maior e outro menor... [...]

- Estou vendo muito camelo nesse miolo da Asia, vóvó... [sic.] (LOBATO, 1935, p. 145).

Este movimento nos remete à figura do narrador, pela qual Lobato se move "para cima e para baixo nos degraus de sua experiência, como numa escada. Uma escada que chega até o centro da terra e que se perde nas nuvens [...]" (BENJAMIN, 1996, p. 215). Nesse movimento de idas e vindas pela memória, o autor resgata o conceito de artesanalidade do conhecimento e a maneira como ele se dispõe na sociedade, chamando a responsabilidade do processo educativo para a própria criança leitora, para seus familiares, seus amigos e para a própria sociedade, em um momento da história em que a abertura democrática da escola abdicava para si a responsabilidade da formação humana que antes cabia à oralidade. Isso tudo feito com muita leveza, fortes doses de imaginação e de criação, como um escape às imposições do fazer literário do início do século XX, quando a experiência leitora da criança passava primeiro pela experiência de mediação do outro, do leitor adulto. Para Zilberman (2008) a literatura, que abarca a sua vertente de teor infantil, possui papel formativo de destaque, já que possibilita o desenvolvimento da oralidade, do imaginário e da abertura para a sensibilidade, cujas experiências literárias tecem relações entre o real e o imaginado.

Lobato se apresenta aos seus leitores como um narrador de um espaço em formação; seus textos, que surgem em meio à presença ainda viva do romantismo literário regionalista brasileiro, apresentam-se como monumentos de resistência da narrativa em uma época de rápida aceleração dos contextos, especialmente o cultural. Diferente do romancista, que escreve a partir da experiência isolada de escritor e que, segundo Benjamin não sabe dar nem receber conselhos, o narrador escreve a partir de sua própria experiência e também da experiência do outro, pois é ele quem tem a função de fazer sugestões "sobre a continuação de uma história que está sendo narrada" (BENJAMIN, 1996, p. 200) mais do que continuá-la ao seu modo, tal como indica a direção do pensamento de Lobato.

\section{O LIVRO DIDÁTICO DE GEOGRAFIA}

A narrativa que tomamos como referência de investigação traz consigo a marca da geograficidade como fio condutor, ou seja, o texto inaugura, ao modo como na História, com a historicidade, uma contextualização espacial das experiências de leitura ao jovem estudante leitor, em que as possibilidades interpretativas se dão a 
partir dos indícios que o texto denota e são atravessadas pelas sensibilidade, pela intuição.

O período histórico compreendido entre o final do século XIX e o início do século XX representa, para o campo da educação escolar, sobretudo, um ponto de viragem. Inicialmente, no registro da história da educação escolar no Brasil, observase que a modalidade de educação formal se executava no ambiente escolar para pequenos grupos de estudantes dos grandes centros urbanos ou mesmo para os descendentes de personalidades político-econômicas, quando em se tratando de regiões distantes dos centros urbanos mais proeminentes.

Na observação ao ambiente de desenvolvimento deste tipo de educação, já no final do século XIX, a literatura brasileira se mostrava presente no apontamento de algumas características marcantes da realidade desta modalidade, muitas vezes denunciando dificuldades enfrentadas no dia a dia escolar, muitas vezes ressaltando aspectos idiossincráticos do meio. Como exemplo mais destacado, o famoso Conto de escola (1844), de Machado de Assis, revela a situação a partir do ponto de vista daquele mais afetado pelo modelo vigente: o estudante. O conto serve como uma lição para se pensar a educação brasileira no início do século XX; em resumo, trata de um episódio da vida escolar de Pilar, cujo desejo de estar fora da sala de aula era maior que a sua vontade de "aprender" por meio de livros, de recitações, de conhecimentos decorativos. A pipa no céu de maio, o som do tambor do pelotão que marchava, a pratinha atirada à rua pelo mestre, tudo que estava fora lhe tinha mais sabor a vida, enquanto dentro da escola só sabor a obrigação. (ASSIS, 1884, s./p.).

O que nos interessa na análise deste conto é o movimento iniciado por Machado de Assis e desenvolvido por outros pensadores da educação infantil brasileira do período, entre eles e, sobretudo, Monteiro Lobato, no sentido do questionamento do cânone do conhecimento adquirido e do conhecimento vivido, ideia que subjaz ao seu pensamento na sua Geografia. O querer sair, viajar na imaginação concreta, mas com respaldo no sonho lúcido e na fantasia possível era o propósito de educação desenvolvido pelo autor brasileiro com sua narrativa geográfica fantástica; aprender dos livros e ir olhar o mundo, ver na vida o que falava a teoria importava-lhe verdadeiramente como aprendizado, bem ao contrário do movimento escolar de sua época, centrado naquilo que Kahn (2014) denomina de "lição de coisas", cuja história funde-se à do livro didático.

Segundo Oriá "[...] é consenso entre os historiadores da educação que se torna quase impossível termos uma definição concisa e, ao mesmo tempo, completa do que seja o livro didático, também conhecido como manual escolar." (ORIÁ, 2011, p. 45). Assim também compreende Bittencourt (1993), que aponta a respeito: "[...] trata-se de uma produção caracterizada por uma diversidade de textos, compêndios, cartilhas, livros de leitura que por vezes se confundem com a nascente literatura infantil e juvenil e por crescimento constante ocasionado pela multiplicação das disciplinas escolares." (BITTENCOURT, 1993, p. 2-3).

$\mathrm{Na}$ realidade da educação escolar francesa para o cânone das disciplinas escolares da Geografia e da História, o pesquisador Pierre Kahn admite que estes foram os campos de conhecimento mais afetados pela introdução do livro didático pelo método das lições de coisas. Segundo este autor, o panorama das lições de coisas prezava pela introdução de conhecimentos que fossem universais, no sentido do "ensinar tudo a todos", o grande alvo das críticas de Lobato com as suas narrativas. Das suas palavras, "[...] a lição de coisas [...] é uma lição de tudo: 'é necessário lembrar-se que a lição de coisas não é um ramo especial de ensino, mas uma forma 
que se adapta a todos os sujeitos, aos mais elevados e mais complexos, como aos mais simples e mais fáceis." (KAHN, 2014, p. 195).

Seguramente, como raiz do descontentamento de Monteiro Lobato com a literatura para crianças de sua época, encontra-se a realidade escolar brasileira, fortemente inspirada na da escola pública francesa e que igualmente promulgava um cenário de promoção de conhecimentos enciclopédicos e decorativos. Importa ressaltar que o período em discussão esteve imerso em ideologias muito significativas do ponto de vista da formação de identidades para as nações que vinham se consolidando desde o século XVIII, tal como a do positivismo, orientado pela lógica de fundamento de uma pátria a partir da industrialização e, principalmente, do conhecimento científico e da razão. Neste sentido, segundo Kahn (2014) a lição de coisas "projeta sobre a escola um complexo de representações no qual a ideia do ensino científico se articula a certos grandes temas de um discurso impregnado de cientificismo - progresso, razão, luzes, moral da ciência [...]" (KAHN, 2014, p. 193).

À época da produção literária infantil de Monteiro Lobato, os livros escolares e de literatura orientada à juventude leitora obedeciam todos a uma lógica eurocêntrica, sobretudo, francesa. O pesquisador Bernard Huber aponta que em finais do século XIX e início do século XX predominava a cultura escolar e infantil dos abecedários; a Geografia, assim, era pretexto para se aprender as letras e alfabetizar-se, e não era tomada como uma disciplina ou ciência distinta. Segundo o autor "desde o fim do século XVIII, e também em todo o XIX, é atribuído à geografia, como a outras disciplinas (as ciências naturais, por exemplo), um papel de pretexto para o exercício das ferramentas de leitura que são as letras e as sílabas [... $]^{3}$ (HUBER, 2001, p. 42 tradução livre).

Contudo, não podemos concluir que a narrativa eleita para estudo se enquadre como livro didático, embora seu empréstimo como leitura corrente em escolas públicas do Brasil tenha se efetivado em períodos posteriores aos de sua produção. Neste sentido, entende-se que a Geografia de Lobato tenha desempenhado importância ímpar na construção de um conhecimento geográfico, inicialmente na escola e, posteriormente, na academia, especialmente pela forma como vieram se construindo ao longo da constituição do que hoje se denomina cultura escolar.

Segundo Boligian e Almeida (2011), os primeiros autores de livros didáticos eram também seus manuseadores, os chamados professores-autores, que contribuíram para o estabelecimento de uma cultura escolar geográfica:

Os professores-autores foram os responsáveis por desenvolverem a didatização dos saberes escolares, de maneira a torná-los assimiláveis aos estudantes, donde recuperam-se os métodos mnemônicos de memorização, reprodução e o clássico "decorar", que impuseram-se como métodos clássicos da assimilação do conhecimento no âmbito escolar. (BOLIGIAN; ALMEIDA, 2011, p. 76 - grifo nosso).

Também, na consideração de que o início da produção dos livros didáticos remonta ao início do século XIX, os pesquisadores admitem que a vulgata, 0 conhecimento adquirido da experiência em sala de aula pelo professor-autor seja um dos alicerces que garantiram a transposição do conhecimento geográfico escolar para

\footnotetext{
3 "Dès la fin du XVIII' siècle, et pendant tout le XIX', est attribué à la géographie, comme à d'autres disciplines (les sciences naturelles, par exemple), un rôle de pretexte pour l'exercice des outils de lecture que sont les lettres et les sylabes [...]” (HUBER, 2001, p. 42).
} 
o ambiente acadêmico, fato que situa a Geografia de Dona Benta, principalmente, como produção ideológica - didática - de peso na consolidação do conhecimento geográfico científico e na formação de um pensamento geográfico acadêmico nacional. Ainda segundo os autores, parte dos conhecimentos geográficos surge na escola antes que na academia, para o que "verificamos que suas origens estão apoiadas em um tipo de saber erudito clássico, baseado no espírito das humanidades, os quais formaram o alicerce do ensino secundário em nosso país, antes da fundação das primeiras universidades." (BOLIGIAN; ALMEIDA, 2011, p. 88 - grifo dos autores).

É neste sentido que Angelo e Albuquerque (2014) compreendem a importância do conhecimento geográfico para a formação de um pensamento nacionalista e patriotista no Brasil e no mundo ocidental. Em pesquisa aos conteúdos divulgados nos livros didáticos escolares regionais brasileiros de Geografia, apontam que:

Para o ensino secundário, a partir da década de 1810, a Geografia enquanto disciplina [escolar] já se fazia presente nas aulas preparatórias para os exames na carreira militar, tendo em vista a cobrança dos conteúdos de caráter geográfico para o ingresso nesses cursos. A partir de 1831 a Geografia torna-se conteúdo obrigatório dos cursos preparatórios e dos exames parcelados dos Cursos Jurídicos [...] (ANGELO; ALBUQUERQUE, 2014, p. 93).

Uma vez que a Geografia se coloca como a ciência dos territórios, ou seja, da relação que o homem estabelece entre as suas ações e o espaço físico, justifica-se caber a essa ciência o papel de fazer o brasileiro conhecer o Brasil. Conforme as pesquisadoras, em uma pesquisa quantitativa por elas realizada sobre a produção brasileira de livros didáticos no período de 1870 a 1910, encontrou-se que a produção de livros para o ensino primário foi de "33\% em relação aos $12 \%$ do secundário." (ANGELO; ALBUQUERQUE, 2014, p. 96).

Os autores de livros didáticos regionais do período estudado escreviam seus compêndios com o intuito de promover o conhecimento a respeito de sua província, estado ou região e de fazer circular a cultura geográfica local e regional, em vista dos projetos nacionalistas que ganharão destaque com os romances literários regionalistas do período, como as obras do cearense José de Alencar, por exemplo, que retratam as origens do homem brasileiro.

No entanto, toda a movimentação dos autores e intelectuais nacionais para a criação de um sentimento patriotista entre o povo brasileiro será desenvolvida no bojo do movimento de maior importância da escola pública brasileira do século $X X$, a Escola Nova, ideologia que ganhará destaque na década de 1930, quando Lobato se debruça sobre a escrita da sua Geografia. Esta proposta de organização e de relação com o conhecimento na escola tinha características que a distinguiam totalmente do modelo anterior das lições de coisas ou abecedários geográficos, para o caso da Geografia: esta escola desejava ser universal, gratuita e pública - regida pelo Estado, em um contexto em que importava acabar com a influência doutrinária da Igreja na educação e fazer com que o Estado tomasse as rédeas da educação nacional.

Contudo, não se pode deixar de notar que eram também preceitos da Escola Nova, como indica Mello (2014), "afastar-se da transmissão autoritária e repetitiva dos conhecimentos, aproximar-se dos processos criativos e menos rígidos de aprendizagem, não isolar a vida comunitária da vida escolar" (MELLO, 2014, p. 149), além de se distanciar dos processos burocráticos do Estado que mais emperravam o sistema educacional que o libertavam; enfim, uma educação escolar pautada no 
"aprender fazendo", de modo mais libertário, fortemente apoiada na subjetividade do estudante como farol para a sua formação, inclusive como leitor de um espaço geográfico nacional e regional em consolidação.

De modo que o Brasil também carecia de uma identidade nacional, bem como seu povo de alguma noção de brasilianidade, como fazer para se construir um sentimento de pertencimento ao mesmo país, ao mesmo território, desde o gaúcho no sul ao indígena no norte amazônico? Evidentemente, a alternativa mais adequada foi encontrada na união pela língua, "o que sobra quando nada mais agrega, quando nada reúne" (BARTHES, 2010, s./p.) e, por extensão, pela leitura e pela escrita, especialmente estimuladas pela literatura infantil.

Como nem o Brasil, nem o brasileiro estavam agregados, logo, o primeiro passo foi buscar unificar a língua ao território, compreendendo que "[...] a nacionalidade deveria firmar-se pelo uso adequado da língua portuguesa de forma uniforme e estável em todo o território nacional." (SCHWARTZMAN; BOMENY; COSTA, 2000, p. 157). E é neste cenário de divulgação de ideologias e de imposição de uma língua como elemento aglutinador ao país que o livro, especialmente o didático, nas escolas, aparece como uma das ferramentas mais significativas e eficazes para este intento.

A subversão dos cânones literários promovida por Monteiro Lobato, especialmente quanto à experiência de espaço geográfico permitida com o elemento de fantasia possível na Geografia de Dona Benta, vem para contrapor-se a este movimento homogeneizante proposto pela literatura a sua época, fortemente amparada no modelo de lição de coisas, enciclopedista e acumulativo e, ainda que apoiado na temática da nacionalização e do ensino, revela ao jovem leitor de seu tempo uma possibilidade de se pensar um fazer literário e espacial outro.

\section{CONSIDERAÇÕES FINAIS}

A narrativa da Geografia de Dona Benta se insere na história da construção do pensamento geográfico e da geografia escolar no Brasil e no mundo ocidental como ponto de partida para se pensar e viver o espaço geográfico a partir de uma concepção que extrapola o meramente racional e objetivo, ao buscar na fantasia e no escape pela imaginação e pela criatividade um modo outro de se pensar e viver esse mesmo espaço e, assim, inaugura uma possibilidade de geografia escolar que nos chega até os dias atuais.

$\mathrm{Na}$ conclusão dos apontamentos traçados, permanece o entendimento de que a Geografia de Dona Benta coloca-se como uma narrativa que, ao mesmo tempo em que surge no movimento escolanovista de revisitação do papel e da organização da escola púbica, também vai na contramão do projeto nacionalista brasileiro de seu período, ao qual a literatura de Lobato coloca-se como resistente ao lançar mão de uma linguagem mágica, como alternativa possível ao contexto de unificação cultural que se impunha no país, além de inaugurar na literatura orientada à infância no Brasil a busca pela leitura criativa.

Ao iniciar e inserir um movimento que prezava pela atenção à língua e à literatura como chaves para o entendimento da formação do espaço nacional brasileiro, a escrita da narrativa de Monteiro Lobato assume um teor de obra de arte, irreplicável, mas possível de ser tomada como inspiração; daí a importância e a vitalidade que dela emanam, para a sobrevivência do pensamento e da liberdade da própria Geografia, ao sentido indicado por Barthes.

A obra literária implica um trabalho composicional específico, uma arquitetônica, que podemos entender como a reunião de imagens, a caracterização 
de personagens, de modos de narrar e de selecionar palavras que fazem parte da arte narrativa e que escapam para uma criação autônoma. Assim ocorre em Lobato: uma Geografia que se tornou autônoma pela força libertadora da literatura e se fez de grande importância para a educação; a Geografia de Dona Benta, que não é uma produção didática, apesar de tomada de empréstimo para este fim, salienta-se justamente pelo fato de conseguir estabelecer relações entre ensinar e aprender sem recorrer à categoria do estritamente didático, um movimento libertador promovido por Lobato à literatura orientada à infância.

Ao refundar a noção de didatismo, Lobato resgata uma noção importante para a educação: a da persistência da literatura como mártir da formação humanizada. Eis aí um duplo movimento, qual seja, o de salvação das letras do arcaísmo cultural e a reinvenção do sentido de aprender, conduzindo à instituição de um terceiro lugar, o do aprendizado pela experiência criadora, cuja literatura consegue melhor fornecer; afinal, conceber uma Geografia contada e não descrita e decorada, criando a especificidade que só a palavra de Lobato conseguira até então, demandaria a revisitação de todo o cânone sobre o conceito de educação.

Como a escrita de Lobato ruma para uma experiência leitora em Geografia a partir da construção de "livros onde se possa morar", pode-se dizer que esta escrita se distancia, por exemplo, da proposta dos livros didáticos contemporâneos a sua obra, elaborados, a princípio, para a qualificação instrumental do jovem estudante. Deste modo, sua obra assume relevância, ao manifestar uma postura de crítica diante da situação política e econômica vivida pelo povo brasileiro e a sua passividade no sentido do agir em favor de uma pátria e de uma nação.

Se o livro didático ora passa a ser importante na fixação de conceitos, ora passa a ser auxiliar no desenvolvimento da formação do leitor, a Geografia de Dona Benta, que não tem o compromisso declarado do didático, dá o suporte para uma experiência leitora em Geografia que é imaginável, sensível e que se aproxima da expressão literária. Essa geografia do faz-de-conta proposta por Lobato captura o conceito de geograficidade proposto por Dardel (2011), o do ser e estar no mundo percebido a partir da experiência de vida no espaço.

Como experiência geográfica, a Geografia de Dona Benta sugere a apropriação sensível do espaço, experiência que é a célula que desperta no leitor a imaginação e vice-versa, e é dela também que deriva a vontade da criação, ingrediente fundamental na receita da imaginação; uma vez que não se cria algo novo, a criação só pode vir da experiência, da junção dos pequenos grãos da criação cotidiana que se vão tecendo e que vão dando corpo às grandes criações.

Ao provar que uma didática do conhecimento geográfico é possível pelo viés literário, a Geografia de Dona Benta refunda uma relação com os saberes sobre o espaço, que passam a exigir do leitor um retorno sensível, que caminha pelos sentidos da imaginação saudável, aquela que dá brecha para o duvidar e para o negar. Uma experiência leitora em Geografia que olha para os pontos opacos dos conhecimentos geográficos, cuja realidade geográfica apresenta lacunas que escapam da atenção do homem, mas que podem ser compreendidas.

Compreendemos que a experiência de leitura e de geografia relativa à narrativa que estudamos assenta-se nas ações de aprender e percorrer: aprender enquanto se percorre um território, uma região, um país e percorrer enquanto se aprende desses lugares, dessas escalas espaciais, entendendo que o conhecimento de caráter geográfico por ela expressado é um conhecimento dinâmico, que não se contenta em apenas realizar-se na teoria. A essa ideia de experiência leitora se faz subjacente a convicção de que ela abre as portas para um outro espaço, para uma outra maneira 
de pertencer ao mundo e, assim, os "escritores nos presenteiam com uma geografia, uma história, uma paisagem onde retomamos o fôlego." (PETIT, 2008, p. 79).

O diálogo entre a Geografia e a literatura apresenta-se como uma ponte que pode enriquecer as análises tanto de uma, quanto de outra ciência. Para o campo da literatura, podemos dizer que sua maior conquista será a precisão das análises e interpretações do uso dos conceitos de espaço nas narrativas, enquanto as análises geográficas se beneficiarão dos recursos do manejo da língua e da cultura letrada na construção do espaço, como com a descrição e a caracterização espacial, por exemplo.

De modo que a literatura se faz uma linguagem universal, privada de liberdade senão somente pela limitação do pensamento e da língua do leitor, é ela o mecanismo mais concreto que permite unir a imaginação ao real, em se permitindo criar novos e outros mundos e espaços, melhores ou mais em acordo com os desejos do leitor. Se a compreensão de que a Geografia melhor se traduz pelas geograficidades, pelo compreender o espaço geográfico pelo que sua voz quer dizer, é pela literatura que esse movimento se torna mais concreto, porque as transformações começam primeiro no nível da imaginação, do desejo e da ficção. Senão na literatura, onde mais o espaço geográfico poderia ser melhor criado?

\section{AGRADECIMENTOS}

Agradecemos pelo apoio financeiro oferecido pela FAPESP (Fundação de Amparo à Pesquisa do Estado de São Paulo) na elaboração desta pesquisa - processo de referência no. 2014/21402-2.

\section{REFERÊNCIAS}

ANGELO, Maria Deusia Lima; ALBUQUERQUE, Maria Adailza Martins de. Autores e livros didáticos regionais de Geografia (1870-1910): elementos históricos e educacionais para uma espacialização do fenômeno. Revista brasileira de educação em Geografia, Campinas [s.n.], v. 4, n. 8, p. 88-112, jul./dez., 2014.

ASSIS, Machado de. Conto de escola. 1884. Disponível: http://www.dominiopublico.gov.br/download/texto/bv000268.pdf Acesso em 14/01/2021.

BARTHES, Roland. Aula. São Paulo: Cultrix, 2010.

BENJAMIN, Walter. O narrador. Considerações sobre a obra de Nikolai Leskov. In: BENJAMIN, Walter. Magia e técnica, arte e política. Ensaios sobre literatura e história da cultura. Tradução de Sérgio Paulo Rouanet. São Paulo: Brasiliense, 1996, p. 197-221.

BITTENCOURT, Circe Maria Fernandes. Livro didático e conhecimento histórico: uma história do saber escolar. 1993. 369 f. Tese de doutorado em História Social. USP - Universidade de São Paulo. São Paulo, 1993.

BOLIGIAN, Levon; ALMEIDA, Rosângela Doin de. A cartografia nos livros didáticos no período de 1824 a 1936 e a história da Geografia escolar no Brasil. In: ALMEIDA, 
Rosângela Doin de. [Org.] Novos rumos da cartografia escolar. Currículo, linguagem e tecnologia. São Paulo: Contexto, 2011, p. 71-90.

CEVASCO, Maria Elisa. Dez lições sobre estudos culturais. São Paulo: Boitempo, 2003.

DARDEL, Eric. O Homem e a Terra. Natureza da realidade geográfica. São Paulo: Perspectiva, 2011.

GINZBURG, Carlo. Sinais: raízes de um paradigma indiciário. In: GINZBURG, Carlo. Mitos, emblemas, sinais - morfologia e história. São Paulo: Companhia das Letras, 1999, p. 143-179.

HUBER, Bernard. Les abécédaires géographiques du XIXe siècle: une "géographieprétexte". Mappemonde, [s.n.] [s.l.], n. 62, p. 42-47, 2001.

KAHN, Pierre. Leçons de choses et enseignement des sciences en la France à la fin du $19^{\mathrm{e}}$ siècle: contribution a une histoire de la culture scolaire. Revista História da Educação, Porto Alegre [s.n.] v. 18, n. 43, p. 183-201, mai./ago., 2014.

LOBATO, Monteiro. Geografia de Dona Benta. 1 ed. v. XXII. Ilustrações de J. U. Campos e Belmonte. São Paulo: Companhia Editora Nacional, 1935, 234p.

MELLO, Márcia Cristina de Oliveira. Os manuais de ensino de geografia produzidos no primeiro terço do século XX: fontes e objetos de estudo. Revista brasileira de educação em Geografia, Campinas [s.n.] v. 8, n. 4, p. 146-159, jul./dez., 2014.

MONTEIRO, Carlos Augusto de Figueiredo. O mapa e a trama: ensaios sobre o conteúdo geográfico em criações romanescas. Florianópolis: Editora da UFSC, 2002.

ORIÁ, Ricardo. O Brasil contado às crianças. Viriato Corrêa e a literatura escolar brasileira (1934-1961). São Paulo: Annablume, 2011, 274p.

PETIT, Michèle. Os jovens e a leitura: uma nova perspectiva. São Paulo: Editora 34, 2008.

SCHWARTZMAN, Simon; BOMENY, Helena Maria Bousquet; COSTA, Vanda Maria Ribeiro. Tempos de Capanema. São Paulo: Paz e Terra, Editora FGV, 2000.

ZILBERMAN, Regina. O papel da literatura na escola. Via Atlântica, [s.n.] [s.I.], n. 14, p. 11-22, 2008. 